\title{
PENINGKATAN STRATEGI PENJUALAN PUPUK KOMPOS PADA BSM SUBUR DI DESA TAMBAK REJA KAB. CILACAP Muhamad Yusuf $^{1}$, Arif Ainur Rafiq ${ }^{2}$, Vicky Prasetia ${ }^{3}$, Supriyono ${ }^{4}$ \\ 1,2,3,4 Politeknik Negeri Cilacap \\ J1. Dr. Soetomo No. 1 Sidakaya Kab. Cilacap. \\ ${ }^{1}$ Email: muhamad.yusuf.1986@gmail.com, 2arifainurrafiq@gmail.com \\ 3 vickyprasetia@gmail.com, ${ }^{4}$ rzx.clcp@gmail.com,
}

\begin{abstract}
ABSTRAK
Permasalahan yang banyak ditemui dalam mayarakat perkotaan adalah masalah sampah, dengan banyaknya jumlah penduduk pada masyarakat perkotaan setiap hari pasti menghasilkan sampah baik organik maupun non organik. Salah satu usaha yang ada di desa Tambak Reja adalah Bank Sampah Mandiri (BSM) SUBUR. Dimana unit usaha utama dari BSM SUBUR adalah pengolahan limbah/sampah menjadi pupuk organik. Kendala yang dihadapi pada unit usaha yang sedang dijalankannya saat ini. Beberapa diantaranya yaitu proses pengemasan produk pupuk organik masih belum menarik. Desain kemasan produk yang menarik dan mampu memberikan informasi produk yang dipasarkan. Desain kemasan produk sebelum dilakukan branding dan setelah diredesain. Hasil kegiatan menunjukkan bahwa produk-produk BSM Subur sudah mulai dikenal oleh masyarakat di luar kabupaten Cilacap.
\end{abstract}

Kata Kunci: sampah, desain produk

\begin{abstract}
The problem that is often found in urban society is the problem of waste, with the large number of residents in urban society every day must produce both organic and non-organic waste. One of the businesses in Tambak Reja village is the Self Garbage Bank (BSM) SUBUR. Where the main business unit of BSM SUBUR is processing waste / garbage into organic fertilizer. Constraints faced in the business unit that is being run at this time. Some of them, namely the process of packaging organic fertilizer products are still not interesting. Attractive product packaging design and able to provide marketed product information. Design product packaging before branding and after redesign. The results of the activities show that BSM Subur products have begun to be recognized by the community outside the Cilacap district.
\end{abstract}

Keywords: waste, product design

\section{PENDAHULUAN}

Desa merupakan unit terkecil dari struktur pemerintah yang sangat dekat dengan masyarakat. Desa juga merupakan unit pemerintah yang berhadapan langsung dengan 
masyarakat. Undang-Undang No. 6 Tahun 2014 tentang Desa mengharuskan kehidupan desa dikelola secara mandiri untuk mencapai kesejahteraan [1],[3]. Presiden melalui Peraturan Pemerintah No. 47 Tahun 2015 tentang Desa mengamanatkan bahwa desa memiliki wewenang untuk mengatur sumber daya dan arah pembangunan [4]. Hal ini menjadi peluang perangkat desa untuk melaksanakan program-program untuk meningkatkan kesejahteraan masyarakat desa dengan memanfaatkan penggunaan sumber daya alam, sumber daya manusia, dan lingkungan secara bijak.

Desa Tambak Reja merupakan salah satu dari 5 desa yang berada di Kecamatan Cilacap Selatan, Kabupaten Cilacap. Desa Tambak Reja dengan luas lahan 155,96 ha (hektar) [2]. Salah satu permasalahan yang banyak ditemui dalam mayarakat perkotaan adalah masalah sampah, dengan banyaknya jumlah penduduk pada masyarakat perkotaan setiap hari pasti menghasilkan sampah baik organik maupun non organik. desa Tambak Reja lokasinya yang berada di kota Cilacap, sehingga banyak UMKM atau jenis-jenis usaha yang bergerak dalam berbagai bidang. Salah satu usaha yang ada di desa Tambak Reja adalah Bank Sampah Mandiri (BSM) SUBUR. Dimana unit usaha utama dari BSM SUBUR adalah pengolahan limbah/sampah menjadi pupuk organik. Hal ini sejalan dengan himbauan yang dilakukan oleh Dinas Lingkungan Hidup yaitu reuse, reduce dan recycle [5]. Dalam hal ini BSM SUBUR telah melakukan kegiatan recycle yaitu mengolah limbah menjadi barang komoditi yang layak jual seperti pupuk organik. BSM SUBUR dipimpin oleh bapak HM. Arif Sartoyo dalam menjalankan usahanya bekerjasama dengan kelompok masyarakat sekitar dan ibu-ibu PKK dalam hal pembuatan produk dan pemasaran produk yang dihasilkan.

Hasil wawancara dengan bapak HM. Aris Sartoyo selaku pimpinan BSM SUBUR ada beberapa kendala yang dihadapi pada unit usaha yang sedang dijalankannya saat ini. Beberapa diantaranya yaitu proses pengemasan produk pupuk organik masih belum menarik. Saat ini BSM SUBUR belum mempunyai mesin pengemasan yang sesuai standar akibatnya produk yang dihasilkan hanya dipasarkan pada warga sekitar. Hal ini berdampak pada menurunnya pendapatan dari usaha ini. Ruanglingkup pemasaran produk BSM SUBUR hanya sebatas pada ibu-ibu PKK yang ada di lingkungan sekitar sehingga cakupan pemasaranya masih belum luas.

Melihat berbagai permasalahan yang dihadapi oleh BSM SUBUR, oleh sebab itu unit usaha ini memerlukan updating teknologi berupa mesin pengemasan yang sesuai dengan standar dan peningkatan pemasaran produk pada marketplace atau media social, agar produk 
dari BSM SUBUR dapat dikenal secara luas [6],[7],[8],[9]. Luaran dari kegiatan ini adalah menghasilkan produk pupuk organik yang dikemas sesuai dengan standar produk, seperti adanya spesifikasi produk juga akan dikemas secara menarik [10]. Diharapkan dengan adanya penambahan mesin pengemasan dan promosi melalui marketplace akan meningkatkan penjualan produk dari BSM SUBUR.

\section{METODE PELAKSANAAN}

Berdasarkan target luaran yang akan dicapai, maka metode pelaksanaan pengabdian kepada masyarakat yang akan dilakukan dalam program pengabdian kepada masyarakat ini adalah sebagai berikut:

1. Melakukan observasi dengan cara survei lapangan dan wawancara pada usaha BSM SUBUR di Desa Tambak Reja, Kecamatan Cilacap Selatan, Kab. Cilacap

2. Analisis kebutuhan data yang dibutuhkan terkait dengan permasalahan yang ada pada usaha BSM SUBUR di Desa Tambak Reja tersebut.

3. Melakukan koordinasi dengan objek untuk menyusun dan membuat kesepakatan tentang proses dan jadwal pelaksanaan program pengabdian kepada masyarakat, agar tidak mengganggu kegiatan rutinitas usaha BSM SUBUR.

4. Memberikan inovasi teknologi pengemasan produk pupuk organik pada BSM SUBUR agar kemasannya lebih menarik konsumen.

5. Memberikan pelatihan tentang strategi penjualan produk pupuk organik untuk kelompok PKK RT 007 RW 008 Desa Tambak Reja, Kecamatan Cilacap Selatan, Kab. Cilacap melalui marketplace dan social media.

6. Melakukan pemasaran produk pupuk kepada kelompok tani yang ada di Cilacap dan diluar Cilacap (banyumas dan kebumen).

7. Melakukan evaluasi terhadap penguasaan materi yang disampaikan, yaitu materi tentang proses pengemasan produk dan strategi penjualan produksi.

8. Melakukan evaluasi dan analisis terhadap hasil dari penerapan teknologi baru untuk proses pengemasan produk dan strategi penjualan yang telah dilakukan.

Prosedur pelaksanaan program yang akan dilaksanakan pada program pengabdian kepada masyarakat ini berupa sebagai berikut: 
1. Observasi, prosedur yang dilaksanakan pada observasi ini yaitu sebagai berikut:

a. Survei lapangan, yang bertujuan untuk mengetahui objek permasalahan secara langsung

b. Wawancara, yang bertujuan untuk mengetahui permasalahan yang dihadapi oleh usaha pengelolaan pupuk kompos BSM SUBUR desa Tambak Reja, Kecamatan Cilacap Selatan.

2. Analisis kebutuhan data, prosedur yang akan dilaksanakan untuk melakukan analisis kebutuhan data adalah dengan mencari informasi terkait yang berupa:

a. Identifikasi peralatan yang sudah ada

b. Proses produksi pembuatan pupuk organik

c. Teknik pengemasan produk yang menarik konsumen

d. Strategi penjualan produk

3. Menyiapkan material, material yang dibutuhkan berupa:

a. Peralatan dan bahan pembuatan teknologi kemasan serta desain kemasan.

b. Strategi penjualan produk pada marketplace atau media sosial

c. Dokumen yang harus dipersiapkan berupa soft copy dan hard copy: file presentasi, media sosialisasi, daftar hadir, dokumentasi, serta file evaluasi analisis dan kinerja pengabdian kepada masyarakat.

4. Pelaksanaan kegiatan, prosedur pelaksanaan kegiatan dapat berupa sebagai berikut:

Evaluasi, prosedur evaluasi dapat dilakukan dengan cara sebagai berikut:

Umpan balik, kegiatan ini dilakukan dengan cara wawancara baik dengan peserta kegiatan yang ikut pada pengabdian masyarakat ini maupun pada masyarakat Desa Tambak Reja dan BSM SUBUR.

\section{HASIL DAN PEMBAHASAN}

Berdasarkan hasil survey dilapangan hampir semua kemasan produk yang ada di BSM Subur kurang memberikan informasi yang memadahi dan kurang menarik konsumen. Hal ini terlihat dari kemasan yang dipakai berupa karung polos yang tidak menampilkan informasi produk. Oleh sebab itu, perlu dibuatkan desain kemasan produk yang menarik dan mampu memberikan informasi produk yang dipasarkan. Desain kemasan produk sebelum dilakukan branding dan setelah diredesain dapat dilihat pada Gambar 1, dimana 
gambar disebelah kiri merupakan desain kemasan produk sebelumnya dan di sebelah kanan adalah desain kemasan produk yang baru.
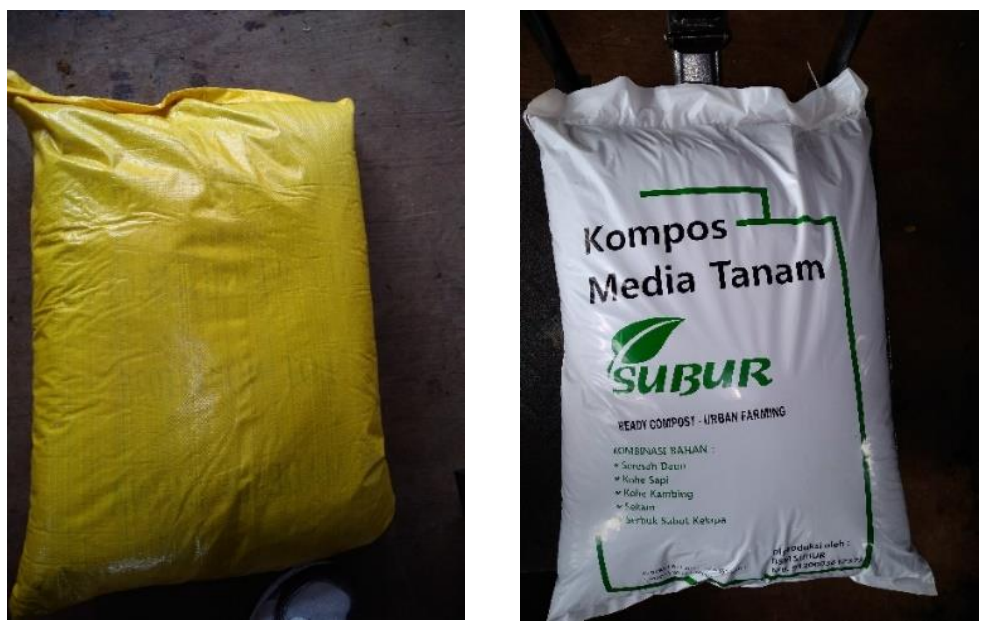

Gambar 1 Desain kemasan produk sebelum dan sesudah

Kegiatan selanjutnya pada pengabdian kepada masyarakat ini adalah pengadaan dan training alat timbang digital dengan kapasitas maksimal $300 \mathrm{~kg}$. jenis timbangan yang diberikan kepada BSM Subur dapat dilihat pada Gambar 2. Timbangan ini sangat mudah penggunaannya dan hasilnya relatif akurat. Pada timbangan digital tersebut juga dapat mengkonversi dari berat menjadi biaya, misalnya $1 \mathrm{~kg}$ pupuk organik mempunyai harga lima ribu rupiah, jika kemasan yang dijual adalah $5 \mathrm{~kg}$, maka secara otomatis pada display akan muncul berat $5 \mathrm{~kg}$ dengan harga Rp.25.000,--

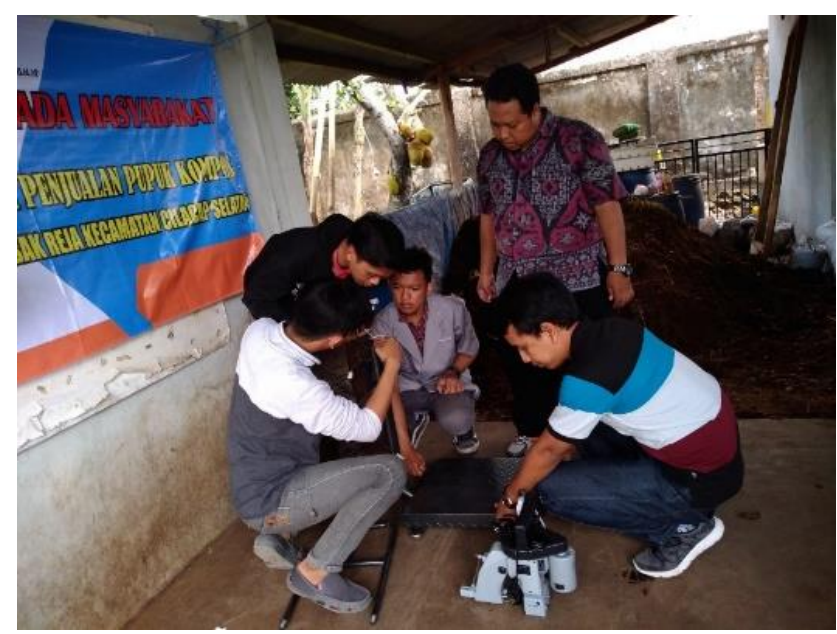

Gambar 2.3 Instalasi dan kalibrasi timbangan 
Semakin banyaknya produk yang dihasilkan oleh BSM Subur, maka diperlukan tempat penyimpanan produk yang baik dan rapi agar dapat menampung banyak produk. Untuk memindahkan suatu produk dari satu tempat ke tempat yang lain diperlukan alat pengangkut. Pada kegiatan pengabdian kepada masyarakat ini BSM Subur diberikan alat penunjang berupa troly pengangkut barang dengan beban maksimal sampai 600kg dengan bantuan berupa troly ini diharapkan proses akomodasi barang dari satu tempat ke tempat yang lain bisa lebih cepat dan mudah. Jenis troly yang diberikan kepada BSM Subur dapat dilihat pada Gambar 3. Troly dilengkapi dengan 2 roda karet dan dua buah gagang pengangkut.

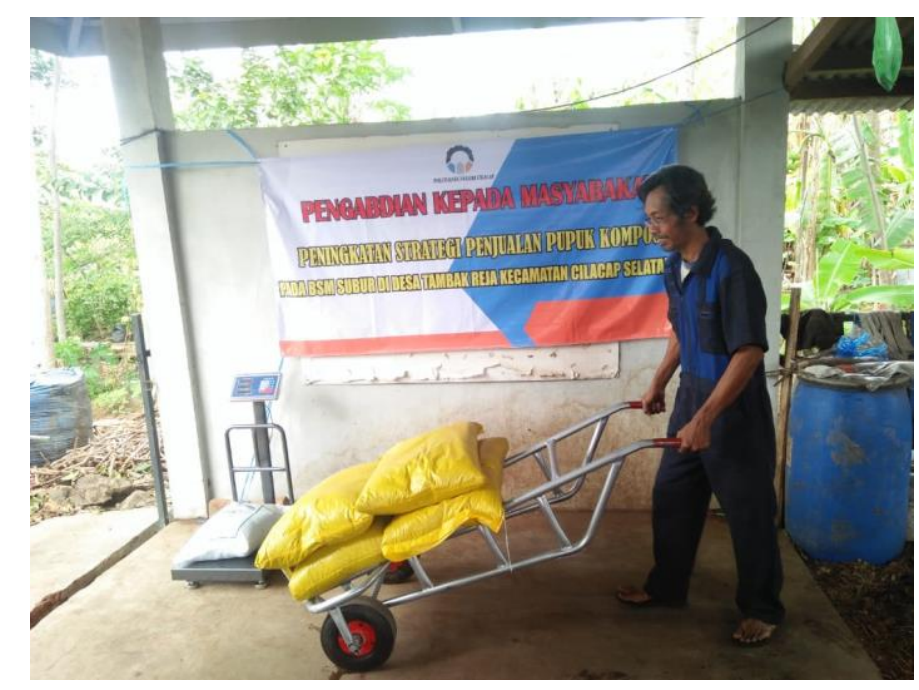

Gambar 4.5 Troly Pengangkut barang

Setelah dilakukan perbaikan sistem pengemasan langkah selanjutnya yakni melakukan sosialisasi. Sosialisasi ini dilakukan kepada warga desa Tambakreja kecamatan Cilacap Selatan yang dikoordinir oleh BSM Subur pimpinan bapak Aris Sartoyo. Beberapa materi yang disampaikan kepada masyarakat adalah pentingnya penggunaan media sosial dan marketplace dalam rangka meningkatkan penjualan suatu produk pada era revolusi industri 4.0 .

Beberapa minggu setelah kegiatan sosialisasi penjualan online dan tutorial pembuatan akun pada marketplace beberapa produk sudah ada yang memesan dari luar Cilacap atau kota Surabaya. Hal ini menunjukkan bahwa produk-produk BSM Subur sudah mulai dikenal oleh masyarakat di luar kabupaten Cilacap. Beberapa kendala yang dihadapi oleh BSM SUBUR dalam hal penjualan secara online adalah sarana dan prasarana bidang teknologi 
informasi khususnya komputer dan HP yang digunakan untuk promosi cenderung menggunakan teknologi yang relatif lama, sehingga hasilnya kurang maksimal.

\section{KESIMPULAN}

Berdasarkan kegiatan pengabdian kepada masyarakat yang sudah dilakukan dapat ditarik beberapa kesimpulan sebagai berikut.

1. Desain produk kemasan yang baru lebih menarik dan memuat semua informasi tentang produk yang akan dijual.

2. Takaran hasil produk lebih presisi bila dibandingkan dengan produk sebelumnya karena sudah timbang.

3. Proses packing lebih cepat dengan adanya mesin jahit listrik portable dan konsumsi daya yang rendah.

4. Proses akomodasi produk satu satu tempat ketempat yang lain lebih cepat dengan bantuan troly.

5. Promosi yang dilakukan secara online terbukti dapat meningkatkan jumlah konsumen, terlihat ada beberapa produk yang dipesan oleh konsumen yang berasal dari luar kabupaten cilacap.

6. Beberapa peserta kesulitan dalam penggunaan HP untuk membuat akun pada market place karena lambatnya jaringan internet yang dimiliki oleh peserta dan spesifikasi HP yang relatif lama.

\section{REKOMENDASI}

Adapun saran yang membangun untuk keberlanjutan kegiatan pengabdian kepada masyarakat ini adalah sebagai berikut.

1. Perlu adanya pendampingan secara berkala terhadap mitra kegiatan pengabdian kepada masyarakat khususnya dalam hal penggunaan teknologi informasi dalam hal menunjang kegiatan penjualan produk, karena kemampuan mitra dibidang teknologi masih kurang maksimal.

2. Perlunya peralatan penunjang dibidang teknologi informasi khususnya computer atau laptop yang memiliki kemampuan cukup baik agar bisa beradaptasi dengan perkembangan software yang ada saat ini, mengingat computer yang ada di mitra tergolong computer dengan spesifikasi cukup lama. 
3. Perlu kegiatan lanjutan dalam rangka promosi produk secara massif dan terus menerus agar produk-produk BSM SUBUR lebih dikenal secara luas.

\section{UCAPAN TERIMAKASIH}

Ucapan terimakasih disampaikan kepada Politeknik Negeri Cilacap yang telah memberikan pendanaan untuk pelaksanaan pengabdian ini dan Pimpinan BSM SUBUR yang telah memberikan izin pelaksanaan pengabdian

\section{DAFTAR PUSTAKA}

Assauri, Sofjan (2008) Proses Produksi dan Operasi. Jakarta: LPFEUI.

Badan Pusat Statistik (2017) Kecamatan Maos dalam Angka 2017. Cilacap :BPS Cilacap. Undang-Undang No. 6 Tahun 2014 tentang Desa.

Peraturan Pemerintah No. 47 Tahun 2015 tentang Desa.

Syarief R dkk (1989) Teknologi pengemasan makanan. Bogor: IPB.

Magdalena H dan Ellyani W (2017) "Strategi Memanfaatkan E-Commerce Dalam Memasarkan Makanan Khas Bangka (Studi Kasus : Aneka Citra Snack)” Cogito Smart Journal/VOL. 3/NO. 2/DEC 2017

Helmalia Dan Afrinawati (2018), "Pengaruh e-Commerce terhadap Peningkatan Pendapatan Usaha Mikro Kecil Dan Menengah Di Kota Padang” JEBI(Jurnal Ekonomi dan Bisnis Islam)-Volume 3, Nomor 2,Juli-Desember 2018

Pitriyani, Kasmi (2017), "Pengembangan Aplikasi E-Commerce Sebagai Media Pemasaran Produk Umkm Di Kabupaten Pringsewu” Jurusan Sistem Informasi, STMIK Pringsewu Lampung

Julisar dan Miranda Eka (2013), "Pemakaian E-Commerce Untuk Usaha Kecil Dan Menengah Guna Meningkatkan Daya Saing” ComTech Vol.4 No. 2 Desember 2013: 638-645

Ni Luh Desi dan Diana Sari (2013), “Elemen Visual Kemasan Sebagai Strategi Komunikasi Produk” Jurnal Komunikasi PROFETIK, Vol. 6, No. 1, April 2013 